\title{
Research on Career Planning Education for College Students of Applied Electric Specialty
}

\author{
Chang Shu', a, Jinshuo $\mathrm{Mei}^{2}$, Jingyu Yang ${ }^{3}$, Yan Sun ${ }^{1}$, Xinxin Chen ${ }^{1}$, \\ Yonglin Yang ${ }^{4}$, Wenpeng Zhang ${ }^{4}$ \\ ${ }^{1}$ Technical School, Harbin University, Harbin 150086, China; \\ ${ }^{2}$ Applied Science School, Harbin University of Science and Technology, Harbin 150080, China; \\ ${ }^{3}$ Technical school, Heihe University, Heihe 164300, China; \\ ${ }^{4}$ Heilongjiang broadcasting bureau, Harbin 150001, China. \\ asum157@163.com
}

\begin{abstract}
Career planning education is of great significance for college students to clear struggle target, enhance their employment ability, and it also promotes the quality of professional education. Whereas the existing career planning education modes for electric specialty student have the problems of lacking pertinence, lacking the whole process and unreasonable composition of the teaching staff. Therefore, according to the characteristics of electric specialty development, how to deepen the cooperation between school and enterprise, integrate the resources and establish the proper model of career planning education has become an urgent problem to be solved. Solving these problems will be important significance to guide the application talents in electric specialty.
\end{abstract}

Keywords: Career planning education; applied undergraduate; electric specialty; employment ability.

\section{应用型电气类专业大学生职业生涯规划教育探析}

舒昌 ${ }^{1}$ ，梅金硕 ${ }^{2}$ ，杨景昱 ${ }^{3}$, 孙妍 ${ }^{1}$, 陈欣欣'，杨永林 ${ }^{4}$ ，张文鹏 ${ }^{4}$

1. 哈尔滨学院工学院, 哈尔滨 中国

2. 哈尔滨理工大学应用科学学院, 哈尔滨 中国

3. 黑河学院工学院, 黑河 中国

4. 黑龙江广播电视局, 哈尔滨 中国

摘 要: 职业生涯规划教育对于大学生明确奋斗目标、提升就业能力, 促进专业提高办学质量 具有重要意义。针对现有的电气类专业大学生职业生涯规划教育模式存在的缺乏针对性、全 程性和师资队伍构成不合理等问题, 以深化校企合作模式为基础, 融合校企资源, 建立符合 电气类专业发展特点的应用型电气类大学生职业生涯规划教育模式, 对于特色应用型电气类 专业人才的培养具有重要指导意义。

关键词：职业生涯规划教育；应用型本科; 电气类专业; 就业能力

\section{1. 前言}

根据中国教育在线数据显示， 2015 年高校应届毕业生人数高达 749 万人，就业形势一年 更胜一年严峻 ${ }^{[1]}$ 。电气类专业的毕业生在择业过程中也遇到了前所未有的挑战。在分析影响 大学生就业的种种因素中，除了当前客观的市场原因之外，电气类专业的职业规划教育不足 也是一个重要的原因 ${ }^{[2]}$ 。长久以来，我国绝大部分高校都缺乏针对应用型电气类专业大学生 相应的大学生职业生涯规划教育, 对学生日后的就业造成了很大的影响。因此, 研究探讨提 
高应用型电气类专业大学生职业生涯规划的有效途径对于促进学生专业学习以及实现高质量 就业都具有重要的积极意义。

\section{2. 应用型电气类专业大学生职业生涯规划的意义}

大学生职业生涯规划是以选择的职业为基础，对主观因素和客观因素进行整合分析，制 定出未来职业的发展目标, 并为此付出行动以实现这个目标的过程 ${ }^{[3]}$ 。应用型电气类专业大 学生职业生涯规划教育则是以应用型电气类专业为背景, 结合专业发展和企业需求特点开展 有针对性的职业规划指导

2. 1. 有利于学生明确奋斗目标, 提升就业能力, 提高就业质量

职业方向是大学生职业生涯规划的首要问题, 也是学生高考填报志愿和四年大学学习所 需面对的重要问题 ${ }^{[4]}$ 。只有确定了发展方向才能制定出合理有效的实施计划并付出努力。当 前部分大学生在步入大学校园后, 认为学习不再是主要任务, 可以完全脱离之前的三点一线 的生活, 有些甚至一直怀揣着进入大学后就可以不再学习的梦想, 而有些家长也开始放松了 管制, 这些都导致部分大学生纪律松散, 缺乏长远目标, 迷失奋斗方向, 部分大学生直到毕 业时还不知道自己喜欢什么职业, 适合哪些岗位, 盲目跟从众人穿梭于各种类型企业招聘会, 最终多次碰壁而失落信心, 出现怀疑自己, 否认自己的不利局面。在当前电气类专业严峻的 就业形式下, 合理的、有针对性大学生职业生涯规划教育可以让学生在学习中认识自己, 了 解自己, 帮助学生更好地了解当前的社会发展形势, 掌握电气类企业的发展动态, 明确日后 的就业方向, 及时调整学习计划, 掌握核心技能, 提升就业能力, 树立正确的人生观和择业 观, 最终实现就业目的, 在激烈的就业竞争形势中找寻出一条适合自己发展的职业道路。

2.2. 有利高校, 企业, 学生三方有机融合, 提高办学质量

应用型电气类专业人才的培养是以电气类专业为基础，以电气类企业的人才需求为培养 目标的培养方式, 而电气类企业存在着发现迅速, 且地域发现不平衡的特点, 这就要求应用 型电气类专业要及时了解当前企业发展状态，不能闭门造车 ${ }^{[5]}$ 。当前部分电气类专业的培养 方案仍然沿用数年前的模式, 虽然也经过一定修改, 但远远不及行业发展步伐, 重理论, 轻 实践的现象并未根本改变, 一些淘汰过时的技术仍然占据大量课时, 而一些企业高需求、有 良好的市场前景的技能却并未得到重视, 学校在封闭或半封闭办学, 与市场脱轨; 而当前部 分电气类企业在行业高速发展的背景下, 时刻以经济效益作为追逐目标, 也并未将行业动态 和自身所需及时反馈给高校, 这些都导致了高校培养目标与企业需求存在差异的结果, 高校 与企业的这些问题最终加剧了本身就对未来迷茫的大学生对四年学习生活的迷失。因此建立 合理、有效的应用型电气类专业的大学生职业生涯规划教育, 可有效地为高校、企业和学生 创建一个融合平台, 企业能够在最少投入的基础上及时指导高校制定出反映市场需求的人才 培养计划, 完成高校的人才培养任务, 又可以减少人力成本, 快速准确地招收到所需要的技 术人才。学生在整个职业生涯规划课程学习中能够及时了解当前行业发展与自身特点, 有的 放矢, 实现高质量就业。因此, 合理的职业生涯规划教育体系能够最终帮助高校、企业和学 生实现三者共赢局面。

\section{3. 当前电气类专业职业生涯规划教育存在的问题}

\section{1 缺乏针对性}

高等教育是以不同专业为基础，来完成社会上所需求的不同类型人才的培养。不同专业 有着不同的学术背景, 不同的技能要求, 也有不同的社会发展特点, 因此, 不同高校的不同 专业往往都具有不同的培养目标和课程体系, 不同专业、不同年级的学生应该有不同的职业 生涯规划指导意见。而目前大部分高校的职业生涯规划设计课程均是以选修课的形式开设, 不同年级和专业的学生在同一课堂下学习相同的内容显然不能充分发挥规划课程的人生指导 作用, 课程内容更多停留在心理辅导和职业生涯规划的理论层面上, 对于不同专业的理论知 
识、实践技能和就业市场等方面的信息指导则难于开展, 职业生涯规划缺乏针对性, 影响课 程指导效果。

\section{2 缺乏全程性}

职业生涯规划指导应该是一个循序渐进的过程，应在学生的不同学习阶段给予相应的指 引。而学生的理解接受能力也是随着他们学习生活的推进不断提高的。因此职业生涯规划课 程的设置不应集中在一个时间点上, 当前的部分高校的职业生涯规划课程却仅仅集中在大一 新生入学或大四将要毕业时期, 这种课程安排夸张一点形容就如同将几十年的的人生指导建 议讲给学前班的孩子或是迟暮老人, 其指导意义自然达不到预期, 因此当前的职业生涯规划 课程体系缺乏全程性得指导。

\section{3 师资队伍构成缺乏合理性}

教师是教育的主体, 教师的学术水平决定了学生的学术高度 ${ }^{[6]}$ 。职业生涯规划课程体系 课程对学生的大学学习生活和今后的职业生涯具有重要的指导意义。考虑到合理的职业生涯 规划指导应具有针对性和全程性的特点, 担任职业生涯规划指导课程的教师应具有丰富的知 识底蕴, 对于专业知识、行业动态与时事以及心理辅导等方面均擅长, 这就要求从事职业生 涯规划课程教学的应是多个层面的师资队伍组合, 而目前大部分高校仅仅采用辅导员或者从 事就业工作的人员单一授课的形式, 限于个人知识涵盖领域, 授课效果必然受到影响, 师资 力量缺乏合理配置。

\section{4. 提高应用型电气类大学生职业生涯规划作用的有效途径}

4.1 建立针对应用型电气类专业特点的大学生职业生涯规划课程体系

应用型电气类人才的培养目标，是为了满足社会上对于具备应用电工电子技术和信息系 统等基础知识的的宽口径 “复合型” 高级工程技术人才需求, 快速适应工作岗位的工程实践 能力、技术应用能力和创新实践能力是毕业生必备的重要技能 ${ }^{[7]}$ 。因此应用型电气类职业生 涯规划课程应以此为基础, 在各个阶段及时对学生的学习予以指引, 每个阶段着重于对当前 行业发展以及前期课程总结和后期课程的指引, 适当增加创新创业和心理辅导课程。大一时 期可开设职业生涯规划理论课程和专业导论。主要针对学生职业方向问题, 改变学生迷失奋 斗方向, 纪律松散现象, 让学生及早认清自身和专业特点, 尽快适应大学学习生活, 初步完 成人生规划。大二时期, 随着专业课进入日程, 各门专业课的特点以及课程之间的联系需强 化教育, 此阶段着重解决学生对专业课程的迷茫, 在大量专业课程同时讲授时, 学生能够对 整体有所了解，增强专业课程学习信心。大三时期着重培养应用型电气类得核心能力, 即工 程实践能力、技术应用能力和创新实践能力, 由于学生已经学习了部分专业课程, 具备一定 的理论基础, 因此此阶段应指导学生学以致用, 这既是对已学课程的检验也是对新学课程的 铺垫, 在增强学生就业技能的同时, 激发对下一阶段的专业课学习兴趣。可引导学生深入实 验室, 参加各类学术比赛, 申报创新创业项目等。大四时期着重于就业的指导, 包括就业观 的指引和就业技巧的培养。电气类企业存在着明显的地域发展不平衡特点, 受国家政策和经 济环境影响比较大, 具有发展变化快的特点, 因此对学生就业观指引环节应及时准确介绍政 策和人才需求分布情况, 及早纠正学生错误的择业观。在就业技巧方面, 应开展简历制作, 面试技巧和模拟应聘等方面的训练, 弥补工科生的不足。另外由于整体就业形式严俊, 学生 在求职时难免会受些挫折, 心理指导方面的课程可在此阶段适时增加, 鼓励学生积极择业。

\section{2 深化校企合作，融合校企资源，加强师资力量建设}

校企合作是当前提高办学质量、提升大学生就业能力的有效手段之一，应用型电气类专 业的职业生涯规划教育应充分利用校企资源, 深化校企合作模式, 完善培养机制, 打造多元 化的教师队伍。

\section{2.1 聘请企业人员以及校内教师组建多元化教学团队}

高校内部包含不同学科, 可挑选从业时间长, 业务精湛的具有心理学, 教育学和专业知 识背景的辅导员、心理咨询师、就业指导教师、职业生涯规划指导教师和专业课教师作为专 
职教师, 聘请企业人力资源顾问、企业培训师和企业工程师等为兼职人员, 力求教学团队学 术背景合理化。

\subsection{2 加强教师到企业实习深造制度，促进校企技术合作，提升教师素质}

电气类企业发展迅速，知识更新换代比较频繁，高校教师应积极深入企业，采取访问， 挂职和技术合作等形式, 不可固步自封, 在提高自身素质的同时, 有利于更新教学内容、提 高教学质量以及及时准确指导学生就业, 对于完成学生职业规划教育都具有积极意义。

4. 2.3 切实加强学生企业实习制度, 将职业生涯规划教育融入到企业实习实践中

企业见习、生产实习以及顶岗实习等实习形式为学生提供了广阔的社会平台, 帮助学生 认识社会、了解行业、大大激发学生学习兴趣, 是应用型电气类人才培养不可或缺的环节, 职业生涯规划教育应充分利用学生企业实习机会, 在学生提升实践技能的同时积极引导学生 结合实际开展自我职业规划, 并以此作为考核实习效果的指标之一, 将职业生涯规划教育和 专业实践教育有机结合，提高企业实习作用。

\section{5. 结论}

电气类专业毕业生在当前严俊的就业形式下面临着前所未有的挑战, 合理有效的大学生 职业规划教育对于缓解学生就业压力, 提升就业质量, 促进专业发展具有积极的作用。针对 目前电气类专业的职业生涯规划教育所存在的缺乏针对性、全面性和师资力量构成不合理等 问题, 应用型电气类专业的职业生涯规划教育应在深化校企合作模式的基础上, 融合校企资 源, 建立针对电气类专业学生特点和符合企业发展现状的的职业生涯规划教育模式。

\section{致谢}

黑龙江省教育科学规划课题省青年专项课题（资助号：GBD1213013）。

\section{References}

[1]. B.R.Dai. Solutions to Alleviating the Employment Pressure of College Students. Theory and Practice of Education. Vol. 34 (2014) No. 18, p.3-5.

[2]. H.R.Sum. Empirical Research on University Students' Profession Career Match from Human Capital Perspective. Human Resources Development of China. Vol. 3 (2015) No. 3, p.77-83.

[3]. W.B.Ma. Career Planning for College Students from the Perspective of System Theory. Journal of Systems Science. Vol. 23 (2015) No. 4, p.88-91.

[4]. Y.C.Li.Investigation and Research on the employment ability of Undergraduates in the application oriented Universities. China Higher Education Research.vol.8(2010),pp.67-69.

[5]. J. X. Zhang.Analysis on the strategies of improving the students' high quality employment ability under the new situation. Heilongjiang Researches on Higher Education.vol.3(2014),pp. 84-86.

[6]. H.Wang, M. L.He. Cultivation of university students' employability based on the perspective of market demand orientation. Logistics Engineering and Management.vol.3(2012),pp. 230-235.

[7]. C.Shu. Research on improving the employment ability of electric information specialty application talents under the cooperation between school and enterprise. International Conference on Management Science and Innovative Education. Wu Han, 2015.12, p. 216-219. 